\title{
Алимов Ф.X. \\ Современные компьютерные технологии и их применение в процессе обучения черчению в профессиональных колледжах (на примере обучения студентов профессионального колледжа по строительству и народному прикладному искусству г. Ташкента)
}

Ташкентский институт инженеров железнодорожного института (Узбекистан, Ташкент)

doi: $10.18411 / l j-28-02-2018-22$

idsp: 000001:lj-28-02-2018-22

\section{Аннотация}

В эпоху современных технологий все сферы жизнедеятельности идут в ногу со временем, стараясь внедрять новые технологические ресурсы. Сфера образования также в числе первых внедряет различные новейшие технологии, которые позволяют учащимся наиболее эффективно усваивать материал. Компьютерные технологии дают возможность на реальных примерах демонстрировать теоретический материал, моделировать и практиковаться учащимся на готовых программных решениях.

В данном материале описан опыт работы с учащимися колледжа прикладного искусства (г.Ташкент, Узбекистан) с применением современных информационных технологий и программ проектирования.

Ключевые слова: информационные технологии, образовательная программа, проектирование, черчение.

XXI век - век информационных технологий, основанный на современных производственных технологиях и технических средствах производства, которые оснащены новейшими компьютерами, а последние в свою очередь современными графическими программами и приложениями.

Идея внедрения компьютерных технологий набирает обороты, и на сегодняшний день практически все учебные заведения г.Ташкента оснащены современными компьютерами, которые позволяют студентам применять, полученные теоретические знания на практике с помощью новых специализированных программ и приложений.

Организации, чья деятельность связана с проектированием объектов, также используют различные компьютерные технологии, что позволяет повысить производительность во много раз. Важно отметить, что выпускники профессиональных колледжей, получившие навыки применения инновационных технологий намного быстрее остальных адаптируются на своих рабочих местах.

На сегодняшний день широко используется большое множество различных программ и приложений, которые облегчают труд проектировщиков и других специалистов смежных направлений. Одной из таких довольно популярных и высокотехнологичных приложений является программа под названием AutoCAD, которая соответствует международным стандартам автоматизированного проектирования.

Направление и специализация, получаемого образования предопределяет ракурс применения компьютерной программы на практике, что делает ее более совершенной в своей области.

Как отмечалось ранее, особое значение придается использованию компьютерных технологий, в частности программ-проектировщиков в рамках обучения различным дисциплинам (например, черчение).

Высокие стандарты и требования предполагают наличие навыков пользования компьютерными технологиями у студентов и преподавателей образовательных учреждений. Однако, стоит отметить, что в настоящее время, на многих этапах образования (от школ до вузов) процесс обучения черчению и прикладному искусству при помощи графических компьютерных программ не на соответствующем уровне. 
Причиной этого является отсутствие высококвалифицированных кадров, что в свою очередь ставит перед нами новые задачи, такие как: разработка новых учебных и методических пособий, повышение квалификации преподавателей, создание площадок для практических занятий и т.д.

Основываясь на собственный профессиональный опыт и вышеизложенные задачи, нами были разработаны электронные учебные пособия, охватывающие трудно осваиваемые темы по курсу «Черчение». Также, нами ведется активная научноисследовательская деятельность по разработке учебных пособий по инженерной и компьютерной графике для учащихся профессиональных колледжей и методик, направленных на формирование необходимых базовых понятий и знаний у учащихся компьютерной графике.

Далее будет представлены некоторые результаты, проведенной нами работы.

1. Впервые на узбекском языке разработано специфическое учебное пособие, состоящее из 18 занятий по инженерной компьютерной графике для учащихся профессиональных колледжей. Пособие состоит из тематического блока, где изложены команды выполнения примитивов чертежа на графической программе AutoCAD-2006 и методических указаний и рекомендаций по выполнению лабораторно-графических работ по специальности.

Эффективность данной методики была апробирована на занятиях, проведенных в профессиональных колледжах. На наш взгляд, применение методики выполнения композиций орнаментов на AutoCAD во всех учебных заведениях, где ведутся курсы народного прикладного искусства, то это принципиально изменит весь процесс обучения.

На рис.1 представлен процесс поэтапного создания полярного геометрического орнамента с двенадцати конечной звездой в центре. На рис.1, а) показана 1/4 часть основной композиции именуемой «Таксим» - составляющий элемент геометрической композиции.
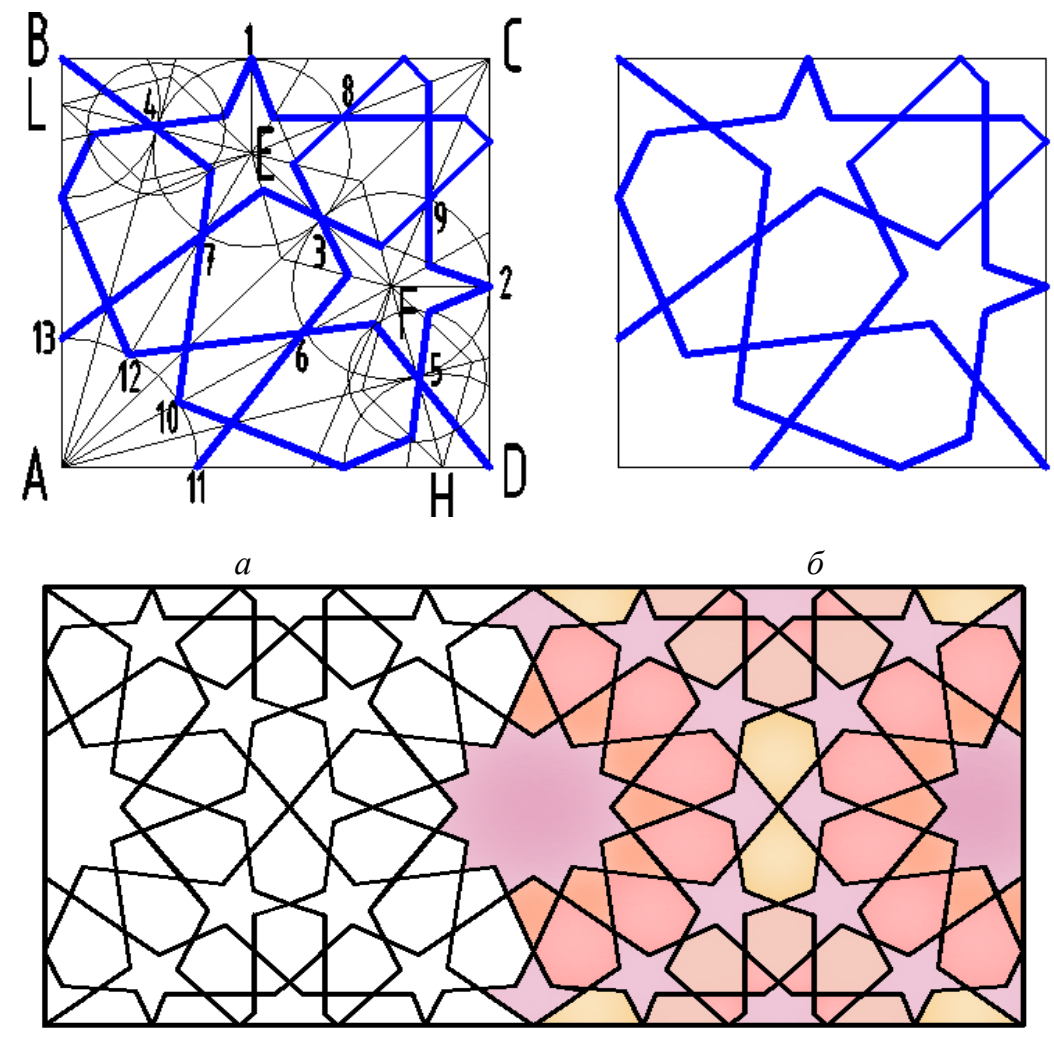

B

Рис. 1. Процесс поэтапного создания полярного геометрического орнамента с двенадиати конечной звездой в иентре 
Для выполнения данной композици “Таксим” нарисован квадрат ABCD. Угол-A разделён пятью лучами на 6 равных частей. Угол С разделён тремя лучами на 4 равные части. При пересечении лучей: 2 (из точки А) и 3 (из точки С), также 4 (из точки А) с 1 (из точки С) получаем центральные пятиконечные звезды, вершины которых являются пересечением остальных лучей. В результате проведения ряда прямых линий, указанных на чертеже и удаляя лишние линии, получим готовую композицию «Таксим» (см. рис.1, б).

Применяя команды «Зеркало» или «Полярный массив» создаем композицию нужных размеров и при помощи команды «Переход» раскрашиваем ее в необходимой цветовой гамме. В итоге, за очень короткое время получаем готовую композицию геометрического орнамента. Причиной выбора именно этой композиции из ряда других видов, применяемых в народном прикладном искусстве, стало то, что именно данная композиция чаще всего используется при национальной росписи объектов.

При помощи уникальных возможностей программы AutoCAD, также можно создавать композиции для резьбы по дереву и по ганчу (смесь гипса с грунтом) в трёхмерном изображении с теневыми оттенками.

Проведённые исследования показали следующие преимущества создания геометрических орнаментов на компьютере: а) высокая точность исполнения композиций; б) экономия времени; в) наличие в программе AutoCAD всех необходимых «инструментов» для выполнения геометрических композиций (многоугольники, круг и др.); г) возможность удаления всех вспомогательных линий одной командой; д) легкость заполнения орнаментом поверхностей различного масштаба; е) возможность автоматического выбора нужного цвета из предоставленной палитры цветов для окрашивания готовой композиции.

Также в рамках данного направления, нами был разработан учебник «Основы компьютерной графики», который на данный момент находится в печати, и очень скоро станет достойным учебным пособием для учащихся профессиональных колледжей соответствующих направлений. Учебник содержит основные понятий по графическим программам FotoShop, CorolDraw, 3Ds MAC, Flash, а также подробное изложение программы AutoCAD.

Как отмечалось ранее, нами разработано электронное пособие стандарта третьего поколения, где подробно описано 6 отдельных проектов. Важно сказать, что все проекты разработаны при помощи последних версий программ 3D MAX, FLASH и AutoCAD. Из дидактики известно, что принцип наглядности, т.е. визуализации какого-либо процесса или графического действия при решении поставленной задачи, является одним из основных факторов повышения эффективности выполнения поставленной задачи, соответственно - успеваемости учащихся. В этом плане современные компьютерные технологии отвечают всем требованиям и обладают такими возможностями, как лёгкость и практичность, демонстрация происходящих графических действий (от начала постановки задач, до итогового результата) в процессе поэтапного решения их двухмерного или трёхмерного изображения.

K примеру, в разработке проекта [1-патент] на тему «Сопряжение» в анимации всесторонне, в двухмерном изображении рассматривается деталь, имеющая контур с сопряжением, то есть плавный переход одной грани в другую (см. рис.2). Затем, графические действия по нахождению центра, точки сопряжения и выполнение самого сопряжения наглядно демонстрируются максимально приближенно к естественному процессу.

При разработке проектов по разрезам, сечениям и пересечениям поверхностей, секущие плоскости в трехмерном изображении рассекают модели и поверхности так же, как в действительности. Отбрасывая часть детали между секущей плоскостью и наблюдателем, показывают оставшуюся часть детали с контуром сечения со штриховкой ее площади. 


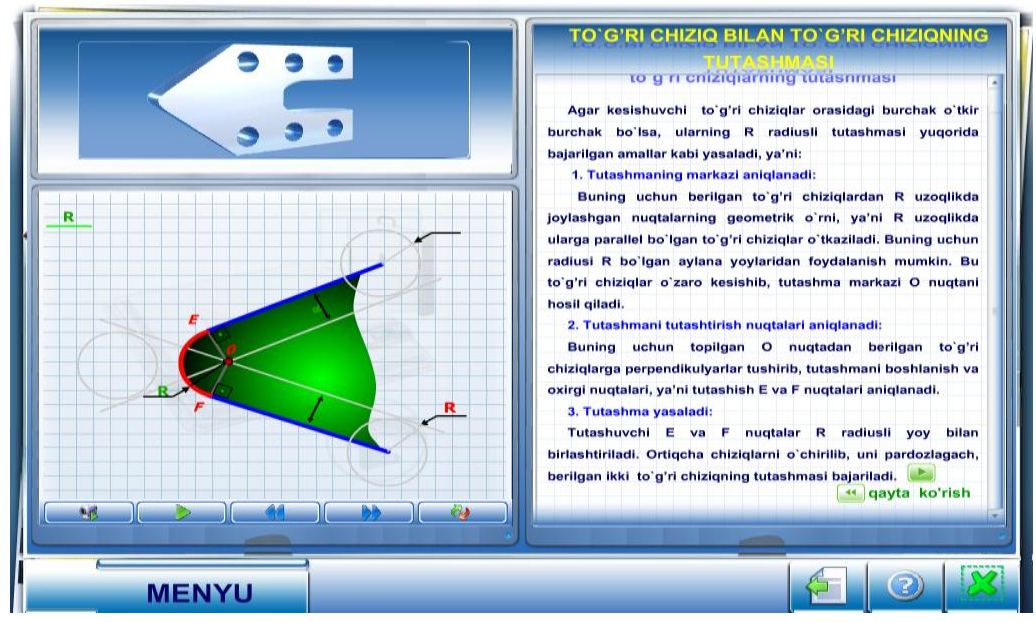

Рис. 2. Проект «Сопряжение»

Таким образом, подробно и достоверно доводится до учащихся весь процесс пересечения тел с плоскостью и получения сечений, а также разрезов. Применение данных электронных учебных пособий непосредственно в учебном процессе, а также при самостоятельной подготовке показало высокую эффективность по трудно усваиваемым темам курса «Черчение», кроме того, вызвало большой интерес у учащихся.

По другому направлению нами ведется научно-исследовательская работа по формированию понятий и знаний у учащихся компьютерной графике на специализированных программах, а также методики преподавания этого предмета. Наши разработки будут полезны учащимся, у которых имеются предварительные знания и навыки по черчению.

Резюмируя итоги работы, хотелось бы отметить, что исследования, проведенные в профессиональном колледже по строительству и народному прикладному искусству, показали, что графическая программа AutoCAD для учащихся вполне доступна и легко осваиваема, что демонстрируют нам работы студентов. Еще важно сказать, что занятия, проведенные с использованием инновационных технологий, вызывают больший интерес у учащихся и повышают качество вырабатываемых навыков.

$$
* * *
$$

1. Касимова С.У. Выполнение геометрических орнаментов при помощи компьютера \Рихсибоев Т. Ташкент.: Педагогическое образование, 2008.-№3.

2. Рихсибоев Т. Компьютерная графика. Ташкент, 2006.

3. Федоренков А., Кимаев A., AutoCAD 2002: «Практический курс». М.: «DESS COM», 2002.

4. Alimov F., Shodimetov X., Ibragimov A. Kompyuter grafikasi va asoslari. "Ozbekiston faylasuflari milliy jamiyati" Toshkent, 2012.

5. www.info-baz.narod.ru.

Апполонова А.А.

Технологизация социальной работы с семьей в системе социальной защиты населения

Комитет по сочиальной политике

(Россия, Калининград)

doi: $10.18411 / l j-28-02-2018-23$

idsp: 000001:lj-28-02-2018-23

\section{Аннотация}

В статье раскрываются некоторые аспекты технологизации социальной работы с семьей в системе социальной защиты населения. Внедрение эффективных технологий 